\title{
Determinantes da Demanda Internacional de Carne Bovina Brasileira: evidências de quebras estruturais
}

\author{
Laércio Juarez Melz ${ }^{1}$, Pascoal José Marion Filho², \\ Reisoli Bender Filho ${ }^{3}$ e Tiane Alves Rocha Gastardelo ${ }^{4}$
}

Resumo: O objetivo deste artigo é verificar as variáveis de impacto na demanda internacional por carne bovina entre janeiro de 1995 e junho de 2013. O método utilizado foi de Mínimos Quadrados Ordinários com Quebras, obtendo-se quatro quebras, cinco regimes. As variáveis independentes na regressão foram os preços de exportação e internos das carnes de bovinos, frangos e suínos, além da renda e da taxa de câmbio. No primeiro regime, a demanda por carne bovina foi elástica em relação aos preços, tanto interno quanto externo, da carne de frango e preço interno da carne bovina. Porém, a elasticidade-renda foi mais significativa. No segundo regime, a relação de preços externos foi inelástica. A elasticidade-renda foi significativa neste regime e houve impacto da taxa de câmbio. No terceiro regime, a demanda foi inelástica em relação aos preços externos das carnes de frango e bovina e elástica aos preços internos das mesmas carnes. A taxa de câmbio também teve impacto significativo. No quarto regime, a demanda foi elástica em relação ao preço interno e inelástica em relação aos preços externos e internos do frango. A renda passa a ser novamente significativa. No quinto regime, a demanda é elástica em relação ao preço externo dos suínos, interno do bovino e à renda. Houve tendência significativa de crescimento no segundo regime e de recessão no primeiro e terceiro regimes.

Palavras-chaves: Cadeia produtiva de carnes, elasticidade da demanda, Mínimos Quadrados com Quebras, bovinocultura.

Abstract: The purpose of this article is to verify impact variables on international demand for beef between January 1995 and June 2013. The method used was Ordinary Least Squares with Breaks, obtaining 4 breaks, 5 regimes. The independent variables in the

1. Doutorando em Administração (UFSM), Professor do Departamento de Ciências Contábeis da UNEMAT-Tangará da Serra, Bolsista FAPEMAT. E-mail: laercio@unemat.br

2. Professor da Universidade Federal de Santa Maria (UFSM). E-mail: pascoaljmarion@yahoo.com.br

3. Professor da Universidade Federal de Santa Maria (UFSM). E-mail: reisolibender@yahoo.com.br

4. Mestranda em Administração (UFSM).E-mail: tianealvesrocha@gmail.com 
regression were the domestic and export prices of beef, chicken and pork, besides income and the exchange rate. In the first regime, the demand for beef was elastic with regard to prices, both internal and external, the domestic chicken and beef prices. However, income elasticity was more significant. In the second regime, the relation of export prices was inelastic. The income elasticity was significant in this regime and the exchange rate had a significant impact. In the third regime, the demand was inelastic to export prices of chicken and beef and inelastic to domestic prices of the same meat. The exchange rate also had a significant impact. In the fourth regime, the demand was elastic to its domestic price and inelastic in relation to external and internal prices of chicken. The income becomes significant again. In the fifth regime, demand is elastic to the external price of pork, domestic bovine price and income. There was a significant increase trend in the second regime and recession in the first and third regimes.

Key-words: Exports, time series, international market, cattle production, Global Value Chain.

Classificação JEL: F02, F17, Q11.

\section{Introdução}

O processo de liberalização da economia brasileira teve início na década de 90, quando foi eliminada grande parte das restrições não tarifárias. Com o "Plano Real", estabeleceu-se o sistema de paridade da moeda brasileira com o dólar americano em 1994. Esse movimento de abertura facilitou as relações comerciais tanto para entrada como para saída de produtos do Brasil (AZEVEDO e PORTUGAL, 1998). O setor agroindustrial foi especialmente favorecido, apresentando crescentes participações no mercado internacional, principalmente de grãos, mas também das carnes de frango, suína e bovina.

A produção de gado bovino tem sido desenvolvida com sucesso no Brasil, desde sua colonização, caracterizada pela grande extensão de terras que favorecem a criação. Segundo dados do USDA (2013), no Brasil, o crescimento do volume de produção da carne bovina de 1995 para 2012 foi de $48 \%$, das exportações foi $568 \%$ e do consumo $31 \%$. Esse cenário de crescimento aconteceu mesmo diante de crises sanitárias, como a da encefalopatia espongiforme bovina e da febre aftosa, além de crises econômicas mundiais como a de 2008. Isso demonstra o grande potencial competitivo do Brasil e a importância de estudos nesta cadeia produtiva. Entre os possíveis estudos nesta cadeia produtiva, está a compreensão da dinâmica entre preços, renda e demanda, chamada de elasticidade ${ }^{5}$. Contudo, é convergente o entendimento de que não somente os preços determinam a demanda, mas também outras variáveis como preços de outras carnes, taxa de câmbio, barreiras tarifárias e não tarifárias. Diversos estudos têm buscado compreender melhor essas relações ao longo dos anos, entre eles, Henneberry e Mutondo (2007), Hupková e Bielik (2009), Gallet (2010, 2012), Resende Filho et al. (2012).

Gallet (2010, 2012) e Resende Filho et al. (2012) ressaltam a importância de estudos sobre elasticidade da demanda em diferentes regiões do mundo como instrumento de auxílio na formulação de políticas públicas e de estratégias empresariais para incentivo ao consumo de carnes. Resende Filho et al. (2012) apontam a escassez de estudos quantitativos sobre demanda agregada de carnes no Brasil. O mesmo ocorre com pesquisas sobre relações entre preços e demanda de carnes brasileiras no mercado internacional, especialmente de carne bovina. Nesse sentido, o objetivo deste trabalho é verificar as variáveis de impacto na demanda internacional por carne bovina entre janeiro de 1995 e junho de 2013. O período selecionado compreende os posteriores à implantação do Plano Real e inserção do Brasil

5. A elasticidade reflete o percentual de variação da demanda em função do percentual de variação no preço ou na renda (PINDICK e RUBINFELD, 2006, VARIAN, 2010). 
no mercado internacional. Pretende-se que esta seja a contribuição deste artigo. Especificamente, busca-se testar a existência de quebras estruturais nas relações entre as variáveis e verificar os motivos das quebras estruturais.

O artigo está estruturado em quatro seções, além desta introdução. Na seção dois é apresentado o mercado internacional da carne bovina brasileira. O modelo teórico de elasticidade da demanda, o método dos Mínimos Quadrados Ordinários com Quebras, utilizado na estimação, as fontes dos dados e testes dos pressupostos e o modelo empírico são apresentados na seção três. A seção quatro inclui os resultados obtidos por meio da regressão e sua discussão. A seção cinco oferece as considerações finais.

\section{O comércio internacional da carne bovina}

Na década de 1990, o comércio mundial de carne bovina enfrentou algumas adversidades. A crise da "vaca louca", como foi chamada a encefalopatia espongiforme bovina (BSE), começou em março de 1996. Naquela época, o governo britânico anunciou uma conexão entre a BSE e a doença de Creutzfeldt-Jakob, que afeta os seres humanos. A partir daí, as autoridades mundiais tornaram-se mais preocupadas com a saúde animal. A doença está relacionada ao uso de ração de base animal para alimentação dos bovinos. Esse problema é minimizado quando o sistema extensivo de criação é utilizado, como acontece no Brasil.

Outra preocupação constante é a febre aftosa que, mesmo não havendo comprovação de prejuízos à saúde humana, a doença tem reflexo no comércio de carne bovina. Em 1998, somente o Rio Grande do Sul e Santa Catarina eram áreas livres de aftosa. Em 2005, a doença volta a afetar Mato Grosso do Sul e Paraná, implicando em suspensão da área livre de Aftosa na maioria dos estados brasileiros. A situação melhorou somente em 2008 quando os estados foram declarados novamente zona livre com vacinação. Em 2011, a grande maioria dos estados foi considerada como zona livre de Aftosa (CFA/MA, 2013). A febre Aftosa impacta principalmente as exportações de carne bovina para mercados mais exigentes como os europeus.

A preocupação com ambas as doenças gerou a necessidade de um melhor controle das origens dos animais. Respondendo a isso, no Brasil, o Ministério da Agricultura, Pecuária e Abastecimento (Mapa) criou um sistema, chamado Serviço de Rastreabilidade da Cadeia Produtiva de Bovinos e Bubalinos (Sisbov), para proporcionar transparência sobre a origem do produto. Para evitar a transmissão de doenças animais entre os estados, a fiscalização em animais vivos transportados tornou-se mais rígida. As dimensões continentais do Brasil também têm seu papel em dificultar a transmissão de doenças entre regiões.

Após a liberalização econômica brasileira em 1990, a cadeia agroindustrial de carne bovina ganhou espaço no cenário mundial. A produção mundial de carne bovina aumentou em 17,1\% entre 1995 e 2012. No mesmo período, o Brasil e a China foram destaques entre os quatro maiores produtores. O Brasil passou de 6 milhões de toneladas produzidas em 1995 para 9,3 milhões em 2012 e China passou de 4,1 milhões para 5,5 milhões de toneladas produzidas, aumentos de 48,5\% e 33,6\%, respectivamente. Em 2005, o Brasil ultrapassou a o volume de produção da União Europeia (UE), permanecendo como segundo maior produtor mundial desde então (Tabela 1).

Em termos de concentração regional da produção (CR4), verifica-se que $60 \%$ da carne bovina mundial é produzida em apenas quatro regiões. Medeiros e Ostroski (2006) classificam esse nível de concentração como moderada. Excluindo-se a União Europeia (UE), que é constituída por 27 países desde 1999 (antes eram 15), a concentração entre os outros três países é de $46 \%$. 
746 - Determinantes da Demanda Internacional de Carne Bovina Brasileira: evidências de quebras estruturais

Tabela 1. Quantidade produzida de carne bovina, principais países, 1995 a 2012, em toneladas e \%

\begin{tabular}{|c|c|c|c|c|c|c|c|c|c|c|}
\hline \multirow{2}{*}{ Ano } & \multicolumn{5}{|c|}{ Quantidade produzida (mil toneladas) } & \multicolumn{4}{|c|}{ Market share } & \multirow{2}{*}{$\begin{array}{c}\text { Var. } \\
\text { Mundo }\end{array}$} \\
\hline & $E U A$ & Brasil & $U E$ & China & Mundo & EUA & Brasil & $U E$ & China & \\
\hline 1995 & 11.585 & 6.080 & 7.964 & 4.154 & 49.021 & $23,6 \%$ & $12,4 \%$ & $16,2 \%$ & $8,5 \%$ & \\
\hline 1996 & 11.749 & 6.150 & 7.950 & 3.557 & 50.200 & $23,4 \%$ & $12,3 \%$ & $15,8 \%$ & $7,1 \%$ & $2,4 \%$ \\
\hline 1997 & 11.714 & 6.050 & 7.889 & 4.409 & 51.789 & $22,6 \%$ & $11,7 \%$ & $15,2 \%$ & $8,5 \%$ & $5,6 \%$ \\
\hline 1998 & 11.804 & 6.140 & 7.624 & 4.799 & 51.796 & $22,8 \%$ & $11,9 \%$ & $14,7 \%$ & $9,3 \%$ & $5,7 \%$ \\
\hline 1999 & 12.124 & 6.270 & 8.803 & 5.054 & 52.906 & $22,9 \%$ & $11,9 \%$ & $16,6 \%$ & $9,6 \%$ & $7,9 \%$ \\
\hline 2000 & 12.298 & 6.520 & 8.325 & 5.131 & 53.037 & $23,2 \%$ & $12,3 \%$ & $15,7 \%$ & $9,7 \%$ & $8,2 \%$ \\
\hline 2001 & 11.983 & 6.895 & 8.120 & 5.086 & 52.482 & $22,8 \%$ & $13,1 \%$ & $15,5 \%$ & $9,7 \%$ & $7,1 \%$ \\
\hline 2002 & 12.427 & 7.240 & 8.310 & 5.219 & 54.113 & $23,0 \%$ & $13,4 \%$ & $15,4 \%$ & $9,6 \%$ & $10,4 \%$ \\
\hline 2003 & 12.039 & 7.385 & 8.287 & 5.425 & 54.376 & $22,1 \%$ & $13,6 \%$ & $15,2 \%$ & $10,0 \%$ & $10,9 \%$ \\
\hline 2004 & 11.261 & 7.975 & 8.350 & 5.604 & 55.620 & $20,2 \%$ & $14,3 \%$ & $15,0 \%$ & $10,1 \%$ & $13,5 \%$ \\
\hline 2005 & 11.318 & 8.592 & 8.136 & 5.681 & 56.127 & $20,2 \%$ & $15,3 \%$ & $14,5 \%$ & $10,1 \%$ & $14,5 \%$ \\
\hline 2006 & 11.980 & 9.025 & 8.191 & 5.767 & 57.659 & $20,8 \%$ & $15,7 \%$ & $14,2 \%$ & $10,0 \%$ & $17,6 \%$ \\
\hline 2007 & 12.097 & 9.303 & 8.258 & 6.134 & 58.597 & $20,6 \%$ & $15,9 \%$ & $14,1 \%$ & $10,5 \%$ & $19,5 \%$ \\
\hline 2008 & 12.163 & 9.024 & 8.130 & 6.132 & 58.550 & $20,8 \%$ & $15,4 \%$ & $13,9 \%$ & $10,5 \%$ & $19,4 \%$ \\
\hline 2009 & 11.891 & 8.935 & 7.923 & 5.764 & 57.376 & $20,7 \%$ & $15,6 \%$ & $13,8 \%$ & $10,0 \%$ & $17,0 \%$ \\
\hline 2010 & 12.046 & 9.115 & 8.101 & 5.600 & 57.567 & $20,9 \%$ & $15,8 \%$ & $14,1 \%$ & $9,7 \%$ & $17,4 \%$ \\
\hline 2011 & 11.983 & 9.030 & 8.114 & 5.550 & 57.410 & $20,9 \%$ & $15,7 \%$ & $14,1 \%$ & $9,7 \%$ & $17,1 \%$ \\
\hline 2012 & 11.849 & 9.307 & 7.711 & 5.540 & 57.558 & $20,6 \%$ & $16,2 \%$ & $13,4 \%$ & $9,6 \%$ & $17,4 \%$ \\
\hline Crescimento no período & $3,4 \%$ & $48,5 \%$ & $1,9 \%$ & $33,6 \%$ & $17,1 \%$ & & & & & \\
\hline CR4 & & & & & & $20,6 \%$ & $36,8 \%$ & $50,2 \%$ & $59,8 \%$ & \\
\hline
\end{tabular}

Fonte: Elaborado pelos autores com dados do USDA (2013).

Apesar da estabilidade na produção, o período entre 1995 e 2002 foi conturbado para os exportadores de carne bovina. A crise da "vaca louca" provocou redução das exportações no período.

Entre os maiores exportadores de carne bovina estão Brasil, Índia, Austrália e Estados Unidos (EUA). Desde 1995, o Brasil tem aumentado sua participação no mercado mundial desta carne. Em 1995, a participação no total exportado representava $4,1 \%$, em 2007 atingiu o pico de $28,7 \%$ de market share. Em seguida, entre 2008 e 2011 houve queda nas exportações brasileiras, como reflexo da crise mundial iniciada no setor imobiliário dos Estados Unidos. Contudo, enquanto as exportações mundiais cresceram $47 \%$, as brasileiras cresceram 568\%, entre 1995 e 2012, revelando sua competitividade. Isso porque no Brasil a criação é extensiva, não utilizando proteína animal na sua alimentação, reduzindo o risco de BSE.

O movimento inverso foi observado pelas exportações dos Estados Unidos, que tiveram um período com pouca participação em 2004
(3,1\%), voltando a crescer até $2012(13,7 \%)$. A Índia pouco exportava em 1995. Devido às crenças religiosas, a carne bovina não é consumida no país, sendo inclusive proibida por leis estaduais e federais (BEEFPOINT, 2013). É interessante que houve crescente participação do país nas exportações mundiais, principalmente após 2000. A explicação é que os dados do USDA incluem os abates de búfalos, que são permitidos na Índia. A Austrália era o principal exportador em 1995, com participação de $20 \%$ no mercado mundial. Teve aumento de $35 \%$ nas suas exportações, menor que a média mundial (47\%), perdendo seu posto de maior exportador para o Brasil em 2005.

A Austrália apresenta quadro com exportações estáveis e aproximadamente $70 \%$ de sua produção é destinada ao mercado externo. A participação de mercado do Brasil, Índia e Austrália é praticamente a mesma, juntos foram responsáveis por 53\% das exportações mundiais em 2012 (Tabela 2). Um nível de concentração moderado, conforme classificação de Medeiros e Ostroski (2006). 
Tabela 2. Quantidade exportada de carne bovina, principais países, 1995 a 2012, em toneladas e \%

\begin{tabular}{|c|c|c|c|c|c|c|c|c|c|c|}
\hline \multirow{2}{*}{ Ano } & \multicolumn{5}{|c|}{ Quantidade Exportada (mil toneladas) } & \multicolumn{4}{|c|}{ Market share } & \multirow{2}{*}{$\begin{array}{c}\text { var. } \\
\text { Mundo }\end{array}$} \\
\hline & Brasil & Índia & Austrália & EUA & Mundo & Brasil & Índia & Austrália & EUA & \\
\hline 1995 & 228 & 196 & 1.109 & 826 & 5.540 & $4,1 \%$ & $3,5 \%$ & $20,0 \%$ & $14,9 \%$ & \\
\hline 1996 & 224 & 204 & 1.026 & 851 & 5.258 & $4,3 \%$ & $3,9 \%$ & $19,5 \%$ & $16,2 \%$ & $-5 \%$ \\
\hline 1997 & 231 & 215 & 1.165 & 969 & 5.827 & $4,0 \%$ & $3,7 \%$ & $20,0 \%$ & $16,6 \%$ & $5 \%$ \\
\hline 1998 & 304 & 245 & 1.247 & 985 & 5.498 & $5,5 \%$ & $4,5 \%$ & $22,7 \%$ & $17,9 \%$ & $-1 \%$ \\
\hline 1999 & 461 & 220 & 1.249 & 1.094 & 5.891 & $7,8 \%$ & $3,7 \%$ & $21,2 \%$ & $18,6 \%$ & $6 \%$ \\
\hline 2000 & 488 & 344 & 1.316 & 1.120 & 5.936 & $8,2 \%$ & $5,8 \%$ & $22,2 \%$ & $18,9 \%$ & $7 \%$ \\
\hline 2001 & 741 & 365 & 1.376 & 1.029 & 5.887 & $12,6 \%$ & $6,2 \%$ & $23,4 \%$ & $17,5 \%$ & $6 \%$ \\
\hline 2002 & 872 & 411 & 1.343 & 1.110 & 6.476 & $13,5 \%$ & $6,3 \%$ & $20,7 \%$ & $17,1 \%$ & $17 \%$ \\
\hline 2003 & 1.162 & 432 & 1.241 & 1.142 & 6.520 & $17,8 \%$ & $6,6 \%$ & $19,0 \%$ & $17,5 \%$ & $18 \%$ \\
\hline 2004 & 1.610 & 492 & 1.369 & 209 & 6.724 & $23,9 \%$ & $7,3 \%$ & $20,4 \%$ & $3,1 \%$ & $21 \%$ \\
\hline 2005 & 1.845 & 617 & 1.388 & 316 & 7.370 & $25,0 \%$ & $8,4 \%$ & $18,8 \%$ & $4,3 \%$ & $33 \%$ \\
\hline 2006 & 2.084 & 681 & 1.430 & 519 & 7.590 & $27,5 \%$ & $9,0 \%$ & $18,8 \%$ & $6,8 \%$ & $37 \%$ \\
\hline 2007 & 2.189 & 678 & 1.400 & 650 & 7.635 & $28,7 \%$ & $8,9 \%$ & $18,3 \%$ & $8,5 \%$ & $38 \%$ \\
\hline 2008 & 1.801 & 672 & 1.407 & 905 & 7.602 & $23,7 \%$ & $8,8 \%$ & $18,5 \%$ & $11,9 \%$ & $37 \%$ \\
\hline 2009 & 1.596 & 609 & 1.364 & 878 & 7.449 & $21,4 \%$ & $8,2 \%$ & $18,3 \%$ & $11,8 \%$ & $34 \%$ \\
\hline 2010 & 1.558 & 917 & 1.368 & 1.043 & 7.820 & $19,9 \%$ & $11,7 \%$ & $17,5 \%$ & $13,3 \%$ & $41 \%$ \\
\hline 2011 & 1.340 & 1.268 & 1.410 & 1.263 & 8.086 & $16,6 \%$ & $15,7 \%$ & $17,4 \%$ & $15,6 \%$ & $46 \%$ \\
\hline 2012 & 1.524 & 1.411 & 1.407 & 1.113 & 8.146 & $18,7 \%$ & $17,3 \%$ & $17,3 \%$ & $13,7 \%$ & $47 \%$ \\
\hline Crescimento no período & $568 \%$ & $620 \%$ & $27 \%$ & $35 \%$ & $47 \%$ & & & & & \\
\hline CR4 & & & & & & $18,7 \%$ & $36,0 \%$ & $53,3 \%$ & $67,0 \%$ & \\
\hline
\end{tabular}

Fonte: Elaborado pelos autores com dados do USDA (2013).

Tabela 3. Quantidade importada de carne bovina, principais países, 1995 a 2012, em toneladas e \%

\begin{tabular}{|c|c|c|c|c|c|c|c|c|c|c|}
\hline \multirow{2}{*}{ Ano } & \multicolumn{5}{|c|}{ Quantidade Importada (mil toneladas) } & \multicolumn{4}{|c|}{ Market share } & \multirow{2}{*}{$\frac{\text { var. }}{\text { Mundo }}$} \\
\hline & Rússia & EUA & Japão & Coréia do Sul & Mundo & Rússia & EUA & Japão & Coréia do Sul & \\
\hline 1995 & 697 & 954 & 922 & 229 & 4.546 & $15,3 \%$ & $21,0 \%$ & $20,3 \%$ & $5,0 \%$ & \\
\hline 1996 & 921 & 940 & 889 & 221 & 5.047 & $18,2 \%$ & $18,6 \%$ & $17,6 \%$ & $4,4 \%$ & $11 \%$ \\
\hline 1997 & 1.018 & 1.063 & 935 & 233 & 5.663 & $18,0 \%$ & $18,8 \%$ & $16,5 \%$ & $4,1 \%$ & $25 \%$ \\
\hline 1998 & 738 & 1.199 & 969 & 129 & 5.420 & $13,6 \%$ & $22,1 \%$ & $17,9 \%$ & $2,4 \%$ & $19 \%$ \\
\hline 1999 & 782 & 1.303 & 986 & 249 & 5.721 & $13,7 \%$ & $22,8 \%$ & $17,2 \%$ & $4,4 \%$ & $26 \%$ \\
\hline 2000 & 425 & 1.375 & 1.045 & 333 & 5.738 & $7,4 \%$ & $24,0 \%$ & $18,2 \%$ & $5,8 \%$ & $26 \%$ \\
\hline 2001 & 671 & 1.435 & 982 & 253 & 5.760 & $11,6 \%$ & $24,9 \%$ & $17,0 \%$ & $4,4 \%$ & $27 \%$ \\
\hline 2002 & 751 & 1.459 & 697 & 442 & 6.203 & $12,1 \%$ & $23,5 \%$ & $11,2 \%$ & $7,1 \%$ & $36 \%$ \\
\hline 2003 & 766 & 1.363 & 833 & 457 & 6.195 & $12,4 \%$ & $22,0 \%$ & $13,4 \%$ & $7,4 \%$ & $36 \%$ \\
\hline 2004 & 791 & 1.669 & 634 & 224 & 6.146 & $12,9 \%$ & $27,2 \%$ & $10,3 \%$ & $3,6 \%$ & $35 \%$ \\
\hline 2005 & 1.054 & 1.632 & 686 & 250 & 6.786 & $15,5 \%$ & $24,0 \%$ & $10,1 \%$ & $3,7 \%$ & $49 \%$ \\
\hline 2006 & 1.033 & 1.399 & 678 & 298 & 6.844 & $15,1 \%$ & $20,4 \%$ & $9,9 \%$ & $4,4 \%$ & $51 \%$ \\
\hline 2007 & 1.115 & 1.384 & 686 & 308 & 7.109 & $15,7 \%$ & $19,5 \%$ & $9,6 \%$ & $4,3 \%$ & $56 \%$ \\
\hline 2008 & 1.227 & 1.151 & 659 & 295 & 6.776 & $18,1 \%$ & $17,0 \%$ & $9,7 \%$ & $4,4 \%$ & $49 \%$ \\
\hline 2009 & 1.053 & 1.191 & 697 & 315 & 6.552 & $16,1 \%$ & $18,2 \%$ & $10,6 \%$ & $4,8 \%$ & $44 \%$ \\
\hline 2010 & 1.057 & 1.042 & 721 & 366 & 6.619 & $16,0 \%$ & $15,7 \%$ & $10,9 \%$ & $5,5 \%$ & $46 \%$ \\
\hline 2011 & 991 & 933 & 745 & 431 & 6.408 & $15,5 \%$ & $14,6 \%$ & $11,6 \%$ & $6,7 \%$ & $41 \%$ \\
\hline 2012 & 1.023 & 1.007 & 737 & 370 & 6.626 & $15,4 \%$ & $15,2 \%$ & $11,1 \%$ & $5,6 \%$ & $46 \%$ \\
\hline Crescimento no período & $47 \%$ & $6 \%$ & $-20 \%$ & $62 \%$ & $46 \%$ & & & & & \\
\hline CR4 & & & & & & $15,4 \%$ & $30,6 \%$ & $41,8 \%$ & $47,3 \%$ & \\
\hline
\end{tabular}

Fonte: Elaborado pelos autores com dados do USDA (2013). 
Os maiores importadores mundiais em 2012 foram Rússia, Estados Unidos, Japão e Coréia do Sul, com participação de $47 \%$ nas compras. Em 1995, a Rússia respondia por $15 \%$ das importações mundiais. Contudo, houve queda de importação entre 1995 e 2004. Em 2005, o país aumentou suas importações em $33 \%$, em relação a 2004. Iniciou-se um ciclo com crescimento médio de $4 \%$ até 2012, levando a Rússia a ser o principal importador mundial. Comparada com o resto do mundo, a Rússia somente acompanhou o crescimento das importações mundiais, que foram de $46 \%$.

Os Estados Unidos vinham aumentando suas importações até 2004, quando participaram de $27 \%$ das compras, em movimento inverso às suas exportações. Porém, suas importações reduziram em 12\% entre 2004 e 2012. Por sua vez, Rússia e Estados Unidos tiveram o mesmo nível de importação em 2012.

O Japão, apesar de continuar como um dos maiores importadores, teve redução de $20 \%$ nas suas importações. Em termos de participação no mercado, o país reduziu em $55 \%$ suas importações. A queda de participação foi mais acentuada entre 2001 e 2002, quando houve redução de $65 \%$. A Coréia do Sul manteve participação estável nas importações, em média 5\% entre 1995 e 2012. Todavia, seu nível de compra é de apenas um terço do maior importador, sendo estável, mas pouco expressivo.

Entre os maiores consumidores de carne bovina estão Estados Unidos, Brasil, União Europeia e China, que juntos consomem 58\% do produto (Tabela 4). Os Estados Unidos mantiveram volume de consumo estável ao longo do período. Em termos percentuais sua participação no consumo mundial caiu de $24 \%$, em 1995, para 21\%, em 2012. É interessante que os Estados Unidos, entre 1995 e 2009, consumiam mais do que sua produção interna, importando, em média, 460 toneladas de carne para suprir sua demanda, em média 3,7\% do consumo. A partir de 2010 , o consumo neste país passou a ser $99 \%$ atendido pela sua produção.

Tabela 4. Quantidade consumida de carne bovina, principais países, 1995 a 2012, em toneladas e \%

\begin{tabular}{|c|c|c|c|c|c|c|c|c|c|c|}
\hline \multirow{2}{*}{ Ano } & \multicolumn{5}{|c|}{ Quantidade Consumida (toneladas) } & \multicolumn{4}{|c|}{ Market share } & \multirow{2}{*}{$\begin{array}{c}\text { var. } \\
\text { Mundc }\end{array}$} \\
\hline & EUA & Brasil & $U E$ & China & Mundo & EUA & Brasil & $E U$ & China & \\
\hline 1995 & 11.726 & 5.993 & 7.356 & 4.051 & 48.186 & $24,3 \%$ & $12,4 \%$ & $15,3 \%$ & $8,4 \%$ & \\
\hline 1996 & 11.903 & 6.147 & 6.883 & 3.457 & 49.638 & $24,0 \%$ & $12,4 \%$ & $13,9 \%$ & $7,0 \%$ & $3 \%$ \\
\hline 1997 & 11.768 & 5.977 & 7.047 & 4.323 & 51.350 & $22,9 \%$ & $11,6 \%$ & $13,7 \%$ & $8,4 \%$ & $7 \%$ \\
\hline 1998 & 12.051 & 5.945 & 7.372 & 4.727 & 51.864 & $23,2 \%$ & $11,5 \%$ & $14,2 \%$ & $9,1 \%$ & $8 \%$ \\
\hline 1999 & 12.325 & 5.865 & 8.659 & 5.017 & 53.212 & $23,2 \%$ & $11,0 \%$ & $16,3 \%$ & $9,4 \%$ & $10 \%$ \\
\hline 2000 & 12.502 & 6.105 & 8.157 & 5.100 & 52.873 & $23,6 \%$ & $11,5 \%$ & $15,4 \%$ & $9,6 \%$ & $10 \%$ \\
\hline 2001 & 12.351 & 6.198 & 7.648 & 5.052 & 52.175 & $23,7 \%$ & $11,9 \%$ & $14,7 \%$ & $9,7 \%$ & $8 \%$ \\
\hline 2002 & 12.737 & 6.445 & 8.329 & 5.214 & 53.910 & $23,6 \%$ & $12,0 \%$ & $15,4 \%$ & $9,7 \%$ & $12 \%$ \\
\hline 2003 & 12.340 & 6.285 & 8.578 & 5.415 & 54.308 & $22,7 \%$ & $11,6 \%$ & $15,8 \%$ & $10,0 \%$ & $13 \%$ \\
\hline 2004 & 12.667 & 6.417 & 8.689 & 5.566 & 55.191 & $23,0 \%$ & $11,6 \%$ & $15,7 \%$ & $10,1 \%$ & $15 \%$ \\
\hline 2005 & 12.664 & 6.795 & 8.605 & 5.614 & 55.620 & $22,8 \%$ & $12,2 \%$ & $15,5 \%$ & $10,1 \%$ & $15 \%$ \\
\hline 2006 & 12.833 & 6.969 & 8.691 & 5.692 & 56.843 & $22,6 \%$ & $12,3 \%$ & $15,3 \%$ & $10,0 \%$ & $18 \%$ \\
\hline 2007 & 12.830 & 7.144 & 8.765 & 6.065 & 57.998 & $22,1 \%$ & $12,3 \%$ & $15,1 \%$ & $10,5 \%$ & $20 \%$ \\
\hline 2008 & 12.403 & 7.252 & 8.398 & 6.080 & 57.690 & $21,5 \%$ & $12,6 \%$ & $14,6 \%$ & $10,5 \%$ & $20 \%$ \\
\hline 2009 & 12.239 & 7.374 & 8.284 & 5.749 & 56.416 & $21,7 \%$ & $13,1 \%$ & $14,7 \%$ & $10,2 \%$ & $17 \%$ \\
\hline 2010 & 12.038 & 7.592 & 8.202 & 5.589 & 56.417 & $21,3 \%$ & $13,5 \%$ & $14,5 \%$ & $9,9 \%$ & $17 \%$ \\
\hline 2011 & 11.646 & 7.730 & 8.034 & 5.524 & 55.710 & $20,9 \%$ & $13,9 \%$ & $14,4 \%$ & $9,9 \%$ & $16 \%$ \\
\hline 2012 & 11.739 & 7.845 & 7.762 & 5.597 & 56.017 & $21,0 \%$ & $14,0 \%$ & $13,9 \%$ & $10,0 \%$ & $16 \%$ \\
\hline Crescimento no período & $0 \%$ & $31 \%$ & $6 \%$ & $38 \%$ & $16 \%$ & & & & & \\
\hline CR4 & & & & & & $21.0 \%$ & $35.0 \%$ & $48.8 \%$ & $58.8 \%$ & \\
\hline
\end{tabular}

Fonte: Elaborado pelos autores com dados do USDA (2013). 
Tabela 5. Ranking e participação de mercado dos quatro maiores importadores de carne bovina brasileira, 1995 a 2013

\begin{tabular}{cccccc}
\hline Ano & Primeiro & Segundo & Terceiro & Quarto & $\begin{array}{c}\text { Participação } \\
\text { Dos 4 maiores }\end{array}$ \\
\hline 1995 & Holanda & Itália & Hong Kong & Reino Unido & $65 \%$ \\
1996 & Holanda & Itália & Espanha & Reino Unido & $71 \%$ \\
1997 & Holanda & Itália & Reino Unido & Espanha & $68 \%$ \\
1998 & Holanda & Itália & Espanha & Israel & $60 \%$ \\
1999 & Holanda & Itália & Chile & Espanha & $54 \%$ \\
2000 & Chile & Holanda & Itália & Reino Unido & $51 \%$ \\
2001 & Chile & Egito & Israel & Holanda & $46 \%$ \\
2002 & Chile & Egito & Arábia Saudita & Rússia & $48 \%$ \\
2003 & Chile & Rússia & Egito & Arábia Saudita & $48 \%$ \\
2004 & Rússia & Egito & Chile & Ira & $47 \%$ \\
2005 & Rússia & Egito & Chile & Reino Unido & $53 \%$ \\
2006 & Rússia & Egito & Reino Unido & Bulgária & $52 \%$ \\
2007 & Rússia & Egito & Ira & Argélia & $57 \%$ \\
2008 & Rússia & Venezuela & Ira & Egito & $61 \%$ \\
2009 & Rússia & Hong Kong & Ira & Egito & $64 \%$ \\
2010 & Rússia & Ira & Egito & Hong Kong & $69 \%$ \\
2011 & Rússia & Ira & Egito & Hong Kong & $65 \%$ \\
2012 & Rússia & Egito & Hong Kong & Venezuela & $61 \%$ \\
\hline
\end{tabular}

Fonte: Elaborado pelos autores com dados de MDIC (2013).

O Brasil consumiu aproximadamente $84 \%$ da carne produzida internamente em 2012. O aumento do consumo no Brasil entre 1995 e 2012 foi de $31 \%$, praticamente o dobro do aumento do consumo mundial $(16 \%)$. O consumo da carne na União Europeia apresentou queda de 1,4\% no mesmo período. $\mathrm{O}$ crescimento do consumo desta comunidade de países foi de $6 \%$ no período. A China também tem sido grande consumidor de carne bovina desde 1995, com sua produção atendendo 99\% de seu consumo em 2012.

A respeito às exportações de carne bovina do Brasil para outros países, percebe-se que as relações comerciais com os principais importadores são estáveis por longos períodos (Tabela 5). A Holanda foi o maior importador entre 1995 e 1999, 5 anos. O Chile passou a ser o maior importador em 2000 e permaneceu nesta posição até 2003, 5 anos. Desde 2004, a Rússia passou a ser o maior importador de carne bovina do Brasil.

Essa relação estável pode ser benéfica na redução de custos de transação entre os países, porém, deve-se observar que existe grande dependência do Brasil em relação aos quatro maiores importa- dores, verificada pela participação média de 58\% nas importações.

Com base nas informações discutidas, pode-se verificar que o Brasil é um grande produtor, consumidor e exportador e carne bovina. Seu principal mercado atualmente é a Rússia, que também é o maior consumidor mundial.

\section{Método}

\subsection{Modelo teórico de elasticidade}

A análise da demanda fornece condições de avaliar como mudanças nas variáveis, entre elas o preço, tendências e sensibilidade do consumidor influenciam as decisões de compra dos agentes. Para as empresas, a previsão da demanda auxilia na determinação da melhor alocação dos recursos para produção de determinado bem de forma a maximizar o lucro. Para os governos a previsão da demanda tem papel de estimar o impacto das políticas públicas na demanda dos bens (GALLET, 2012; RESENDE FILHO et al., 2012). 
Partindo do pressuposto de que os indivíduos procuram sempre otimizar suas decisões, haveria um limite de preços que o consumidor estaria disposto a pagar (VARIAN, 2010). Os consumidores, segundo Pindick e Rubinfeld (2006), têm limitações financeiras e, por isso, com base em suas preferências, maximizam o próprio bem-estar optando por comprar umas unidades de um bem e, em contrapartida, adquirir menos de outro. Em termos percentuais, a elasticidade preço é definida como a variação da demanda causada pela variação nos preços de determinado bem, dada pela Equação (1).

$$
\mathrm{E}_{\mathrm{p}}=\frac{\Delta \mathrm{Q} / \mathrm{Q}}{\Delta \mathrm{P} / \mathrm{P}}=\left(\frac{\mathrm{P}}{\mathrm{Q}}\right)\left(\frac{\Delta \mathrm{Q}}{\Delta \mathrm{P}}\right)
$$

em que, $P$ é o preço e $Q$ é a quantidade de um determinado bem. $\Delta \mathrm{Q} / \mathrm{Q}$ reflete a variação percentual da quantidade demandada e $\Delta \mathrm{P} / \mathrm{P}$ é a variação percentual do preço entre dois períodos. A demanda pode ser classificada, a partir do resultado desta formulação, em elástica, unitária ou inelástica. A demanda é inelástica quando aumentos de preço ocasionam apenas uma pequena variação na quantidade demandada, com resultado menor que $1\left(\mathrm{E}_{\mathrm{p}}<1\right)$ em números absolutos. Demanda unitária acontece quando o percentual de variação das quantidades é exatamente igual ao percentual de variação dos preços $\left(E_{p}=1\right)$ e demanda elástica ocorre quando o resultado é maior que $1\left(E_{p}=1\right)$.

O impacto da variação da renda na demanda por um bem é chamado de elasticidade-renda da demanda. Varian (2010) informa que a elasticidade-renda é medida pela equação:

$$
\mathrm{E}_{\mathrm{r}}=\frac{\Delta \mathrm{Q} / \mathrm{Q}}{\Delta \mathrm{R} / \mathrm{R}}
$$

em que $\Delta \mathrm{Q} / \mathrm{Q}$ é a variação percentual nas quantidades e $\Delta R / R$ é a variação percentual nos preços. Quando o resultado da equação é $1\left(E_{\mathrm{r}}=1\right)$ é considerado um bem normal, quando é menor que $1\left(E_{\mathrm{r}}<1\right)$ é um bem inferior e quando maior que $1\left(E_{\mathrm{r}}>1\right)$ é um bem superior (VARIAN, 2010, p. 285). Isso indica que, quando o bem é inferior, seu consumo é necessário sendo consumido por pessoas em todas as faixas de renda. Ao contrário, um bem superior somente será consumido quando as faixas de renda são maiores. Quanto maior esse coeficiente, maior a renda necessária para o consumo do bem.

Quanto maior a elasticidade preço da demanda de um produto, permanecendo a renda constante, maior sua propensão à substituição do bem por outro (FERGUSON, 1989). Pindick e Rubinfeld (2006) afirmam que alterações nos preços de bens relacionados também afetam a demanda. Os bens são substitutos quando um aumento no preço de um deles leva a um aumento na quantidade demandada do outro. Essa relação é chamada de elasticidade preço cruzada e pode ser demonstrada pela equação log-log (3):

$$
\log (\mathrm{Q})=\mathrm{a}-\mathrm{b} \log (\mathrm{P})+\mathrm{b}_{2} \log \left(\mathrm{P}_{2}\right)+\mathrm{c} \log (\mathrm{R})
$$

Em que:

$\log (\mathrm{Q})$ : logaritmo da variação na quantidade demandada $(\log (\Delta \mathrm{Q} / \mathrm{Q}))$;

a: intercepto da curva da demanda;

$\mathrm{b} \log (\mathrm{P})$ : logaritmo da variação de preço do bem $(\log (\Delta \mathrm{P} / \mathrm{P}))$;

$\mathrm{b}_{2} \log \left(\mathrm{P}_{2}\right)$ : logaritmo da variação do preço do bem substituto ou complementar $\left(\log \left(\Delta \mathrm{P}_{2} / \mathrm{P}_{2}\right)\right)$; e c $\log (\mathrm{R})$ : logaritmo da variação na renda (log $(\Delta \mathrm{R} / \mathrm{R}))$.

Greene (2011) afirma que os modelos com logaritmos permitem uma interpretação dos coeficientes na forma de percentual. Observa-se que na equação Pindick e Rubinfeld (2006) consideram a quantidade demandada, como variável dependente e os preços do bem e seus substitutos, além da renda como variáveis independentes. Pindick e Rubinfeld (2006, p. 118) afirmam que "quando $b_{2}$, que é a elasticidade de preço cruzada, for positiva, os dois bens serão substitutos, quando $b_{2}$ for negativa, eles serão complemento um do outro".

Além de incluir as variáveis de preço e renda, a função de elasticidade da demanda internacional deve considerar variáveis relacionadas a este mercado. Resende Filho et al. (2012, p. 49) afirmam que outras variáveis, além do preço e gasto 
afetam a demanda por carnes, devendo ser incluídas no modelo. Nesse sentido, pode-se verificar que Barros, Bacchi e Burnquist (2002) utilizaram como variável dependente a quantidade exportada e, como independentes, os preços no mercado externo e interno, a taxa de câmbio real e a renda nacional real. Assim, a função de exportação, dada como:

$$
\mathrm{S}^{\mathrm{x}}=\mathrm{f}(\mathrm{Pe}, \mathrm{Pi}, \mathrm{E}, \mathrm{R})
$$

Em que:

$S^{x}$ : quantidade exportada por unidade de tempo; $\mathrm{Pe}$ : preço recebido pelas exportações;

$\mathrm{Pi}$ : preço recebido no mercado interno pelo produto;

E: taxa de câmbio real efetiva; e

$R$ : renda nacional real.

O modelo teórico da elasticidade da demanda estabelece que existem relações estáveis entre preços, renda e a demanda pelos bens. O mesmo acontece com a função de exportação, porém, com a inclusão do cambio como variável influente neste espaço de análise.

\subsection{Testes econométricos}

Para que o modelo de regressão seja suficientemente explicativo é preciso cumprir certos pressupostos (GUJARATI e PORTER, 2011). Contudo, os pressupostos de estacionariedade, normalidade e homocedasticidade dos dados podem ser relaxados quando estão presentes nos resíduos de uma regressão. Para verificar a estacionariedade das variáveis, realizou-se o teste de raiz unitária de Dickey-Fuller Aumentado - $\mathrm{ADF}^{6}$ (GREENE, 2002), a partir da formulação (5):

$$
\Delta \mathrm{y}_{\mathrm{t}}=\mu+\beta \mathrm{t}+\gamma \mathrm{y}_{\mathrm{t}-1}+\sum_{\mathrm{j}=1}^{\mathrm{p}} \gamma_{\mathrm{j}} \Delta \mathrm{y}_{\mathrm{t}-\mathrm{j}}+\varepsilon_{\mathrm{t}}
$$

Em que:

y: é a variável dependente;

$\mu$ : é a constante;

6. O teste ADF é o mais comum. Contudo, pode-se aplicar os testes de Philips-Perron, Kwiatkowski-Phillips-SchmidtShin (KPSS), entre outros, com a mesma finalidade. t: é o tempo;

$j$ : é o número de defasagens de tempo; e

$p$ : é o número máximo de defasagens para somatória.

O teste ADF é uma estimação autorregressiva, com tantas defasagens quantas necessárias, até que o erro seja ruído branco, ou seja, que não há nenhuma informação adicional contida nele (BUENO, 2011). O teste tem como hipótese nula, $\mathrm{H} 0: \gamma=0$, presença de raiz unitária, e $\mathrm{H} 0: \gamma>0$, ausência de raiz unitária. Os valores críticos propostos por MacKinnon (1996) foram utilizados para rejeitar a hipótese nula. Esta verificação foi feita para as variáveis em nível e em primeira diferença. Caso as séries sejam não estacionárias, torna-se necessário verificar se possuem a mesma ordem de integração, cujo objetivo está em detectar se há relacionamento de longo prazo entre as séries, ou seja, cointegração.

O teste Engle-Granger foi utilizado para testar cointegração entre as séries. Engle e Granger (1987) afirmam que duas ou mais séries são cointegradas de ordem $d, b$, denotadas por $x_{\mathrm{t}} \sim C I(d, b)$, se todos os componentes de $x_{\mathrm{t}}$ são $I(d)$, existe um vetor $\alpha(\neq 0) \operatorname{com} z_{\mathrm{t}}=\alpha^{\prime} x_{\mathrm{t}} \sim I(d-b), b>0$. O vetor $\alpha$ é chamado de cointegrado quando rejeita-se a hipótese existência de raiz unitária nos resíduos de uma regressão.

Para testar a normalidade dos resíduos utilizou-se o teste Jarque-Bera ${ }^{7}$, conforme Gujarati e Porter (2011). A homocedasticidade foi testada a partir do teste de White, sob hipótese nula de ausência de heterocedasticidade (WHITE, 1980). A regressão foi estimada com erros padrão robustos para autocorrelação e heterocedasticidade de Newey e West (1987). Para detectar presença de autocorrelação foi utilizada a estatística DurbinWatson (DURBIN e WATSON, 1950, 1951). O software Eviews 8 foi utilizado para realizar a regressão e os testes econométricos.

7. Para uma curva normalmente distribuída, assimetria deve ser $S=0$ e a curtose deve ser $K=3$. Neste caso a hipótese nula é de que existe uma distribuição normal. 


\subsection{Mínimos Quadrados com Quebras}

Foi adotado o modelo de mínimos quadrados com quebras estruturais múltiplas, sugerido por Bai e Perron $(1998,2003)$, que considera um algoritmo baseado em programação dinâmica no qual são estimados modelos com períodos diferentes minimizando a soma dos quadrados dos resíduos. Esse modelo foi escolhido porque admite que as relações entre as variáveis independentes e a dependente são dinâmicas ao longo do tempo. Bai e Perron (2003) consideram que uma regressão linear múltipla pode apresentar $m$ quebras, sendo:

$$
y_{t}=x_{t}^{\prime} \beta+z_{t}^{\prime} \delta_{j}+\mu_{t} \quad t=T_{j-1}+1, \ldots, T_{j}
$$

para $j=1, \ldots, m+1$. Neste modelo, $\mathrm{y}_{\mathrm{t}}$ é a variável dependente observada em um tempo $t$; $\mathrm{x}_{\mathrm{t}}(\mathrm{p}+1)$ e $\mathrm{z}_{\mathrm{t}}(\mathrm{q}+1)$ são vetores de covariância e $\beta \mathrm{e}$ $\delta_{\mathrm{j}}(\mathrm{j}=1, \ldots, \mathrm{m}+1)$ são os vetores dos coeficientes; $\mu_{\mathrm{t}}$ é um distúrbio em um tempo $t$. As quebras estruturais $\left(T_{1}, \ldots, T_{\mathrm{m}}\right)$ são tratadas como desconhecidas, utilizando-se a convenção de que $T_{0}=0$ e $T_{\mathrm{m}}+1=$ T. Quando um dos $\beta$ 's não está sujeito a mudanças ao longo da amostra completa há quebra parcial. Quando $p=0$ acontece uma quebra estrutural pura, neste caso, todos os coeficientes dos regressores são alterados. A variância do erro $\mu_{\mathrm{t}}$ neste modelo, não precisa ser constante, desde que as quebras de variância sejam coincidentes com as quebras nos parâmetros da regressão (BAI e PERRON, 2003). Formalmente, o modelo (6) pode ser expresso em forma matricial, da seguinte forma:

$$
\mathrm{Y}=\mathrm{X} \beta+\bar{Z} \delta+\mathrm{U}
$$

em que $\left.Y=\left(\mathrm{y}_{1}, \ldots, \mathrm{y}_{\mathrm{T}}\right), \mathrm{X}=\left(\mathrm{x}_{1}, \ldots, \mathrm{x}_{\mathrm{T}}\right), \mathrm{u}, \ldots, \mathrm{uy}_{\mathrm{T}}\right)^{\prime}$, $\delta=\left(\delta_{1}^{\prime}, \delta_{2}^{\prime}, \ldots, \delta_{\mathrm{m}+1}^{\prime},\right)^{\prime}$ e $\bar{Z}$ é a matriz com diagonal $\mathrm{Z}$ no $T_{1}, \ldots, T_{\mathrm{m}}$. Para cada $m$ quebra $\left(T_{1}, \ldots, T_{\mathrm{m}}\right)$, a regressão por Mínimos Quadrados Ordinários (MQO) associada é obtida pela minimização dos quadrados dos resíduos.

$$
\begin{aligned}
& (Y-X \beta-\bar{Z} \delta)^{\prime}(Y-X \beta-\bar{Z} \delta)= \\
& =\sum_{i=1}^{m+1} \sum_{t=T_{i-1}+1}^{T_{i}}\left[y_{t}-x_{t}^{\prime} \beta-Z_{t}^{\prime} \delta_{i}\right]^{2}
\end{aligned}
$$

na qual $\hat{\beta}\left[\left\{T_{j}\right\}\right]$ e $\hat{\delta}\left[\left\{T_{j}\right\}\right]$ representam as estimativas baseadas em $m$ quebras $\left(T_{1}, \ldots, T_{\mathrm{m}}\right)$ denotadas por $\left\{T_{j}\right\}$. Substituindo na função objetivo e denotando a soma resultante do quadrado dos resíduos como $S_{\mathrm{T}}\left(T_{1}, \ldots, T_{\mathrm{m}}\right)$, as quebras estimadas são $\left(\hat{\mathrm{T}}_{1}, \ldots, \hat{\mathrm{T}}_{\mathrm{m}}\right)$, tal que $\left(\hat{\mathrm{T}}_{1}, \ldots \hat{\mathrm{T}}_{\mathrm{m}}\right)=\operatorname{argmin}_{\mathrm{T}_{\mathrm{T}}, \ldots, \mathrm{T}_{\mathrm{m}}} \mathrm{S}_{\mathrm{t}}\left(\mathrm{T}_{1}, \ldots, \mathrm{T}_{\mathrm{m}}\right)$ na qual a minimização é considerada em todas as quebras $\left(\mathrm{T}_{1}, \ldots, \mathrm{T}_{\mathrm{m}}\right)$ como $\mathrm{T}_{\mathrm{i}}-\mathrm{T}_{\mathrm{i}-1} \geq \mathrm{q}^{2}$. Os parâmetros da regressão são estimados de forma associada às $m$ quebras $\left\{T_{j}\right\}$, como que $\hat{\beta}=\hat{\beta}\left[\left\{T_{j}\right\}\right]$ e $\hat{\delta}=\hat{\delta}\left[\left\{T_{j}\right\}\right]$ . As quebras são testadas sequencialmente iniciando-se o teste entre 0 versus 1 , em seguida 1 versus 2 quebras e avançando até o que as $m$ quebras ( $L$ versus $L+1$ quebras) atinjam o ponto ótimo, no qual minimiza-se a soma dos quadrados dos resíduos (SSR).

Os intervalos entre quebras são chamados de regimes. Portanto, para cada quebra estrutural será somado 1 para saber o número de regimes. Por exemplo, quando existe 1 quebra estrutural, há 2 dois regimes, um antes e outro após a quebra. Quando existem $m$ quebras, existem $m+1$ regimes.

\subsection{Modelo empírico e fontes de dados}

Não existem muitos trabalhos recentes sobre a estimação da elasticidade da demanda no Brasil que utilizaram séries temporais. Estudos realizados no país datam da década de 1980. O estudo mais recente foi realizado por Resende Filho et al. (2012), que utilizaram Almost Ideal Demand System (AIDS). Porém, a abordagem do modelo considera o período como um todo, não examinando as mudanças estruturais que podem ocorrer ao longo do tempo.

Considerando que a demanda de carne bovina brasileira depende de seu preço, dos preços das carnes de frango e bovina, tanto no mercado interno, quanto internacional e, ainda, que há impacto do câmbio e da renda, o modelo empírico utilizado foi definido como: 
$\log \left(Q_{-} B_{\mathrm{tj}}\right)=\beta_{0}+\beta_{1} \log \left(\right.$ PE_ $\left._{\mathrm{t}_{\mathrm{j}}}\right)+$

$+\beta_{2} \log \left(P E \_B_{t j}\right)+\beta_{3} \log \left(P E \_F_{t j}\right)+\beta_{4} \log \left(P I S_{t j}\right)+(9)$

$+\beta_{5} \log \left(\right.$ PI_B $\left.B_{\mathfrak{t j}}\right)+\beta_{6} \log \left(\right.$ PI_F $\left._{\mathrm{t}_{\mathrm{j}}}\right)+\beta_{7} \log \left(\mathrm{R}_{\mathrm{tj}}\right)+$

$+\beta_{8} \log \left(\mathrm{E}_{\mathrm{tj}}\right)+\mathrm{T}+\varepsilon_{\mathrm{ij}}$

em que:

$Q_{-} B$ : quantidade exportada de carne bovina em quilogramas/mês;

PE_S: preço médio mensal recebido, em dólares americanos (Free On Board - FOB), por quilograma de carne suína exportada. Obtido dividindo-se o valor exportado pela quantidade exportada em quilogramas;

PE_B: preço médio mensal recebido, em dólares americanos (FOB), por quilograma de carne bovina exportada. Obtido dividindo-se o valor exportado pela quantidade exportada em quilogramas;

PE_F: preço médio mensal recebido, em dólares americanos $(\mathrm{FOB})$, por quilograma de carne de frango exportada. Obtido dividindo-se o valor exportado pela quantidade exportada em quilogramas;

PI_S: preço médio mensal da carne suína para atacado em São Paulo, cotado em reais e deflacionado pelo Índice Geral de Preços (IGP-DI), a preços constantes;

PI_B: preço médio mensal da carne bovina para atacado em São Paulo, cotado em reais e deflacionado pelo IGP-DI, a preços constantes;
PI_F: preço médio mensal da carne de frango para atacado em São Paulo, cotado em reais e deflacionado pelo IGP-DI, a preços constantes;

$R$ : PIB mensal do Brasil em reais deflacionado pelo IGP-DI;

$E$ : taxa de câmbio real efetiva média mensal (dólar comercial para venda);

$T$ : é uma tendência temporal;

$\varepsilon_{\mathrm{T}}$ o o termo de erro aleatório com distribuição normal, isto é, média zero e variância constante;

$t$ : período de tempo em meses; e

$j$ : regime de quebras estruturais.

Os dados de exportação e preços externos foram obtidos no banco de dados Aliceweb do Ministério do Desenvolvimento, Indústria e Comércio Exterior (MDIC, 2013). Foram coletadas as quantidades exportadas em quilos e seus preços em dólares. Os preços das carnes foram obtidos pela divisão do valor das exportações em dólares pelas quantidades em quilos. As séries tem periodicidade mensal e correspondem ao período de janeiro de 1995 a junho de 2013, totalizando 222 observações. O ano inicial foi escolhido por ser o primeiro ano pós Plano Real e o final foi o último período disponível até o início da coleta. Foram agregados os produtos de carnes exportados pelo Brasil nos grupos Bovino, Suíno e Frango (Quadro 1).

Quadro 1. Composição dos agregados de carnes

\begin{tabular}{|c|c|c|}
\hline Agregado & NCM & Descrição \\
\hline \multirow{4}{*}{ Bovino } & 0202.10 .00 & Carcaças e meias-carcaças de bovino, congeladas \\
\cline { 2 - 3 } & 0202.20 .10 & Quartos dianteiros não desossados de bovino, congelados \\
\cline { 2 - 3 } & 0202.20 .20 & Quartos traseiros não desossados de bovino, congelados \\
\cline { 2 - 3 } & 0202.20 .90 & Outras pecas não desossadas de bovino, congeladas \\
\cline { 2 - 3 } & 0202.30 .00 & Carnes desossadas de bovino, congeladas \\
\cline { 2 - 3 } & 0201.30 .00 & Carnes desossadas de bovino, frescas ou refrigeradas \\
\hline \multirow{4}{*}{ Frango } & 0207.13 .00 & Pedaços e miudezas, de galos/galinhas, frescos/refriger. \\
\cline { 2 - 3 } & 0207.14 .00 & Pedaços e miudezas, comest. de galos/galinhas, congelados \\
\cline { 2 - 3 } & 0207.11 .00 & Carnes de galos/galinhas, n/cort. pedaços, frescas/refrig. \\
\cline { 2 - 3 } & 0207.12 .00 & Carnes de galos/galinhas, n/cortadas em pedaços, congel. \\
\hline \multirow{5}{*}{ Suíno } & 0203.11 .00 & Carcaças e meias-carcaças de suíno, frescas ou refriger. \\
\cline { 2 - 3 } & 0203.12 .00 & Pernas, pás, etc. não desossad.de suíno, frescos ou refrig. \\
\cline { 2 - 3 } & 0203.19 .00 & Outras carnes de suíno, frescas ou refrigeradas \\
\cline { 2 - 3 } & 0203.21 .00 & Carcaças e meias-carcaças de suíno, congeladas \\
\cline { 2 - 3 } & 0203.22 .00 & Pernas, pás e pedaços não desossados de suíno, congelados \\
\cline { 2 - 3 } & 0203.29 .00 & Outras carnes de suíno, congeladas \\
\cline { 2 - 3 } & & \\
\hline
\end{tabular}

Fonte: Elaborado pelos autores com dados do MDIC (2013). 
O Produto Interno Bruto (PIB) brasileiro foi obtido no banco de dados do IPEA e atualizado pelo Índice Geral de Preços - Disponibilidade Interna (IGP-DI) com base em agosto de 2013. Os preços internos das carnes em séries mensais para atacado na cidade de São Paulo, também atualizados pelo IGP-DI de agosto de 2013. Escolha semelhante foi feita por Resende Filho et al. (2012), justificando-se por ser um grande centro comercial e de consumo.

\section{Resultados e discussão}

A Figura 1 mostra o comportamento das séries entre janeiro de 1995 e junho de 2013. A média de quilos exportados de carne bovina no período de janeiro de 1995 a junho de 2013 foi de 53 milhões, alcançando um máximo de 187 milhões de quilos, no mês de maio de 2010 e um mínimo de 736 mil quilos em janeiro de 1995. O mês com maior volume exportado foi maio de 2010, quando o volume atingiu 187 milhões de quilos.

Quanto aos preços internacionais, percebe-se que os preços da carne bovina foi, em média, $102 \%$ maior que o da carne suína e $249 \%$ maior que o da carne de frango. Assim, espera-se que seu impacto na demanda seja maior que o das duas outras carnes. Quanto ao comportamento ao longo do tempo, os preços externos das carnes bovinas iniciaram um período de quedas em 1995 que seguiu até fevereiro de 2002, quando o preço foi o menor de todos. A partir de 2002 ocorreram sucessivos aumentos de preços até agosto de 2008. Em setembro do mesmo ano, os preços caíram acentuadamente, mas em abril de 2009

Figura 1. Evolução das variáveis entre jan/1995 e jun/2013
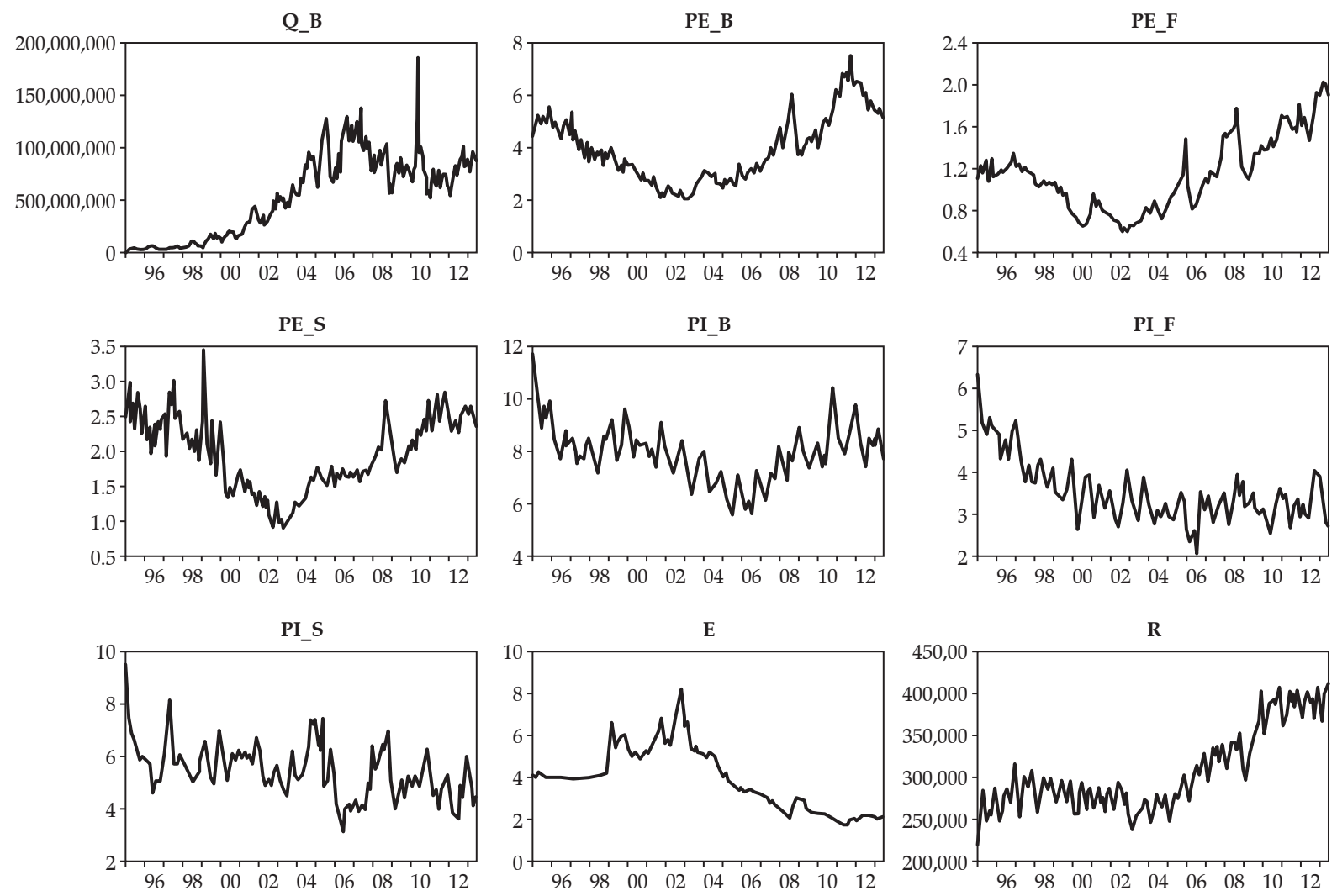

Nota: Q_B é a quantidade exportada de carne bovina, PE_B é o Preço Externo do Bovino, PE_F é o Preço Externo do Frango, PE_S é o Preço Externo do Suíno, PI_S é o Preço Interno do Suíno, PE_B é o Preço Interno do Bovino, PI_F é o Preço Interno do Frango, e R é a Renda e E é a taxa de câmbio. Fonte: Dados da pesquisa (2013). 
voltaram e a crescer e aumentaram até setembro de 2011, quando o preço atingiu o máximo de US\$ $7,53 / \mathrm{kg}$. Desde então, os preços continuaram em queda até o final da série. $\mathrm{O}$ mesmo movimento pode ser observado para os preços do frango e dos suínos, com depressão entre os anos de 2002 e 2003.

Os preços internos apresentam características semelhantes aos externos, porém com intensidade menor. Em relação à carne suína, o preço da carne bovina no mercado interno é $45 \%$ maior e, em relação ao da carne de frangos, é $125 \%$ maior, em média. Os preços internos da carne bovina apresentaram queda até atingirem o menor preço, $\mathrm{R} \$ 5,67$, em julho de 2006. Os menores preços das carnes de frango e suínos também foram registrados neste mesmo mês. As quedas nos preços internos e aumentos dos preços externos fazem com que seja mais atrativo exportar o produto.

Com relação às variáveis macroeconômicas inseridas no modelo, câmbio e renda, a taxa de câmbio do dólar atualizada, variou entre $R \$ 1,76$ e $\mathrm{R} \$ 8,18$, com média de $\mathrm{R} \$ 3,89$ no período de janeiro de 1995 e junho de 2013. O Brasil tem adotado um regime de câmbio flutuante com bandas desde 1999. Percebe-se que, naquele ano houve uma supervalorização do dólar, evidenciado na Figura 1 (E) e quedas sucessivas a partir de 2002 até o final da série.
A renda nacional, representada pelo Produto Interno Bruto (PIB) do Brasil apresentou variação, valores correntes, entre R $\$ 412$ bilhões e R\$ 219 bilhões no período analisado. Sua média foi $\mathrm{R} \$ 307$ bilhões no período. Observa-se na Figura $1(\mathrm{R})$ que a renda nacional tem crescido desde 2002 até 2013, especialmente a partir de 2010. Um aumento da renda faz com que o consumidor procure mais bens superiores e deixe de consumir bens inferiores.

O exame visual permitiu conhecer o comportamento das séries utilizadas no modelo. $\mathrm{O}$ teste de Bai-Perron verifica o número de quebras estruturais que existem em uma regressão por Mínimos Quadrados Ordinários (MQO), testando $1+m$ quebras até que o coeficiente de determinação $\mathrm{R}^{2}$ ajustado seja o melhor possível. A Tabela 6 mostra o resultado do teste, indicando a existência de quatro quebras estruturais, ocorridas nos meses 10/1998, 04/2002, 07/2006 e 05/2010.

O modelo com quebras estruturais permite que em cada período seja estimada uma equação diferente, refletindo os diferentes impactos que as variáveis independentes têm sobre a variável dependente. Assim, diferentes sinais, coeficiente e níveis de significância são permitidos em cada período entre as quebras (regime), conforme demonstrado na Tabela 7.

Tabela 6. Teste de Bai-Perron para seleção do número de quebras estruturais

\begin{tabular}{|c|c|c|c|}
\hline Break Test & F-statistic & Scaled F-statistic & Critical Value ${ }^{* *}$ \\
\hline 0 vs. $1^{*}$ & 1.779 .486 & 1.779 .486 & 27.03 \\
\hline 1 vs. $2 *$ & 3.005 .519 & 3.005 .519 & 29.24 \\
\hline 2 vs. $3 *$ & 1.887 .139 & 1.887 .139 & 30.45 \\
\hline 3 vs. $4 *$ & 2.999 .951 & 2.999 .951 & 31.45 \\
\hline 4 vs. 5 & 0.000000 & 0.000000 & 32.12 \\
\hline \multicolumn{4}{|c|}{ Break dates: } \\
\hline & Sequential & Repartition & \\
\hline 1 & 2002M07 & 1998M10 & \\
\hline 2 & 1998M10 & 2002M04 & \\
\hline 3 & 2006M07 & 2006M07 & \\
\hline 4 & 2010M05 & 2010M05 & \\
\hline
\end{tabular}

* Significativo no nível de 0,05; ** Valores críticos conforme Bai e Perron (2003).

Fonte: Dados da pesquisa (2013). 
Tabela 7. Estimação do modelo de Mínimos Quadrados Ordinários com Quebras

\begin{tabular}{|c|c|c|c|c|c|}
\hline Variável & $\begin{array}{c}\text { 1995M01 } \\
\text { 1998M09 } \\
(45 \text { obs) } \\
j=1 \\
\end{array}$ & $\begin{array}{c}1998 \mathrm{M} 10 \\
2002 \mathrm{M} 03 \\
(42 \mathrm{obs}) \\
j=2\end{array}$ & $\begin{array}{c}2002 \mathrm{M} 04 \\
2006 \mathrm{M} 06 \\
(51 \mathrm{obs}) \\
j=3\end{array}$ & $\begin{array}{c}2006 \mathrm{M} 07 \\
2010 \mathrm{M} 04 \\
(46 \text { obs) } \\
j=4 \\
\end{array}$ & $\begin{array}{c}2010 \mathrm{M} 05 \\
2013 \mathrm{M} 06 \\
(38 \mathrm{obs}) \\
j=5\end{array}$ \\
\hline $\mathrm{C}$ & $16,5444^{* * *}$ & $-9,0933$ & $17,0264^{* *}$ & $10,7470^{* * *}$ & $30,5258^{* * *}$ \\
\hline LOG(PE_S) & $-0,0245$ & $-0,5942^{* * *}$ & 0,1683 & $-0,1244$ & $1,2488^{* * *}$ \\
\hline LOG(PE_B) & $-0,1875$ & $-0,7915^{* * *}$ & $0,5033^{* * *}$ & 0,3596 & $-0,6137^{*}$ \\
\hline LOG(PE_F) & $-1,1949^{* * *}$ & $-0,6866^{* * *}$ & $-0,6622^{* * *}$ & $-0,6435^{* * *}$ & 0,2884 \\
\hline LOG(PI_S) & $-0,1957$ & 0,1688 & $0,3496^{*}$ & 0,1599 & 0,0162 \\
\hline LOG(PI_B) & $-3,6837^{* * *}$ & $-1,0551^{* *}$ & $-2,4099 * * *$ & $-1,3328^{* * *}$ & $-1,5704^{* * *}$ \\
\hline LOG(PI_F) & $-1,6252^{* * *}$ & $-0,4782$ & $1,2684^{* * *}$ & $0,4372^{* * *}$ & $-0,1417$ \\
\hline LOG(R) & $-0,4567$ & $2,0047^{* * *}$ & $-0,1094$ & $0,8788^{* * *}$ & $-0,6928$ \\
\hline LOG(E) & $11,4412^{* * *}$ & $2,1283^{* * *}$ & $0,7052^{* * *}$ & $-0,3707$ & $1,6676^{* * *}$ \\
\hline $\mathrm{T}$ & $-0,0144^{* *}$ & 0,0083 & $0,0283^{* * *}$ & $-0,0100^{* * *}$ & $-0,0065^{*}$ \\
\hline
\end{tabular}

Nota: *** significativo a 1\%, ** significativo a 5\%, * significativo a 10\%, Q_B é a quantidade exportada de carne bovina, PE_B é o Preço Externo do Bovino, PE F é o Preço Externo do Frango, PE S é o Preço Externo do Suíno, PI S é o Preço Interno do Suíno, PE B é o Preço İnterno do Bovino, PI F é o Preço Interno do Frango, e R é a Renda, E é a taxa de câmbio e T é a tendência temporal. A regressão foi estimada com os seguintes parâmetros: Break selection: Trimming 0.15, Max. breaks 5, Sig. level 0.05; HAC standard errors \& covariance (Quadratic-Spectral kernel, Andrews bandwidth $=4.2404$ ). $R^{2}$ ajustado $=0,9877$.

Fonte: Dados da pesquisa (2013).

O primeiro regime $(j=1)$ iniciou em jan./1995 e permaneceu até o set./1998. Esse período coincide com o período de adoção do câmbio flexível com bandas no Brasil. Os preços externos das carnes bovina e suína não apresentaram impacto significativo na demanda internacional por carne bovina. O preço da carne de frango, por outro lado, apresentou relação inversa (negativa) com coeficiente de 1,19 . Isso significa que para cada aumento de $1 \%$ nos preços internacionais desta carne, havia uma redução de $1,19 \%$ no volume exportado de carne bovina. Assim, a carne de frango era bem complementar da carne bovina no mercado internacional. $\mathrm{O}$ impacto dos preços internos da carne bovina e de frango também foi significativo neste período. Para cada aumento de $1 \%$ dos preços internos da carne bovina ou na carne de frango, uma redução de $3,68 \%$ ou $1,64 \%$ acontecia na demanda, respectivamente. Porém, o maior impacto era causado pela taxa de câmbio, o aumento de $1 \%$ no preço do dólar impactava em $11 \%$ no aumento das exportações. Todavia, havia uma tendência de pequena queda na demanda no período de $0,01 \%$.

O segundo regime $(j=2)$ iniciou em out./1998 e terminou em abr/2002. Esse foi o momento do reconhecimento da primeira zona livre de Aftosa no Brasil, os estados de Rio Grande do Sul e Santa Catarina. Neste período, o impacto dos preços externos é significativo, porém menor do que no primeiro regime. Verifica-se que os sinais dos coeficientes dos preços externos são todos negativos, assim, reduções em quaisquer dos preços refletiam em aumentos de demanda por carne bovina, comportamento de bens complementares. A renda brasileira impactava positivamente em $2 \%$ na demanda internacional por carne bovina. Além disso, o impacto do câmbio era de $2,12 \%$, muito menor que o impacto no regime anterior. Vale lembrar que o Brasil adotou o regime de câmbio flutuante em 1999.

O terceiro regime $(j=3)$ aconteceu entre abr./2002 e jun./2006. Neste período acontece uma relação positiva entre o preço internacional da carne bovina e sua demanda, inconsistente com a teoria. Neste período o mundo inteiro havia superado a crise da "vaca louca", aumentando as exportações de carne bovina em $11 \%$ e 9\% nas importações, entre 2001 e 2002. O preço interno teve relação inversa com a demanda internacional, com impacto de $2,4 \%$ de redução na demanda para cada aumento de $1 \%$ naquele. 
O preço externo da carne de frango apresentou comportamento de bem complementar da carne bovina. O preço interno desta carne teve impacto significativo positivo na demanda por carnes bovinas neste período. A taxa de câmbio, já com regime flutuante consolidado, também impactou positivamente na demanda internacional por carnes bovinas. Neste período houve pequena tendência de crescimento nas exportações.

O quarto regime $(j=4)$ iniciou em jul./2006 e terminou em abr./2010. Neste período houve retrocesso no combate à febre Aftosa, fazendo com que muitos dos estados brasileiros fossem classificados como "zona livre com reconhecimento suspenso". Os preços internos e externos da carne de frango e internos da bovina, além da renda e da tendência foram significativos. Sendo impactos negativos registrados nos preços interno do bovino e externo do frango e da variável de tendência. Impactos positivos na demanda foram ocasionados pelos preços internos do frango, além da renda. Portanto, a redução da demanda por carne bovina aconteceu devido ao aumento do preço do frango no mercado internacional e da renda do Brasil, além da queda no preço interno das carnes de frango e bovina.

No último e mais recente regime $(j=5)$, entre maio/2010 e jun./2013, menos relações significativas foram observadas. Esse período coincide com a maior desvalorização cambial experimentada pelo Brasil desde 1995. Apenas o preço externo da carne suína, interno da bovina e a taxa de câmbio foram significativos. O preço externo da carne suína apresentou impacto positivo de 1,2, denotado ser um bem substituto à carne bovina. O preço interno da carne bovina apresentou relação inversa com a demanda internacional, assim, redução de preços da carne bovina no Brasil fizeram aumentar suas exportações. A taxa de câmbio também apresentou relação positiva com a demanda internacional. Seu impacto que vinha diminuindo ao longo dos períodos nos quais ocorreram as quebras estruturais, apresentou aumento, passando de 0,88 , no regime 4 , para 1,66 , no regime 5 .
Em relação a outras pesquisas, pode-se comparar os coeficientes dos preços externos no modelo aqui apresentado, pois, ao foco desta pesquisa é o mercado internacional. Outra diferença é que os demais modelos não utilizam quebras estruturais, assim as comparações podem ser feitas com os regimes em separado. Neste sentido, os resultados deste artigo estão de acordo com os trabalhos de Hupková e Bielik (2009) e Resende Filho et al. (2012) em alguns regimes e contrariam em outros. Os resultados se assemelham aos de Hupková e Bielik (2009) e Resende Filho et al. (2012) em relação preço próprio, no regime 2 e contrariam, para o próprio preço, no regime 3 . $\mathrm{O}$ preço-cruzado do suíno, nesta pesquisa, confirma os resultados dos mesmos autores no regime $5 \mathrm{e}$ contraria no regime 2. Hupková e Bielik (2009) encontraram uma relação não significativa do preço do bovino com o preço do frango, diferente do resultado obtido nesta pesquisa. Aqui, todos os regimes tiveram impacto significativo do preço externo do frango na demanda pelo bovino. Resende Filho et al. (2012) apresentaram comportamento inverso do preço-cruzado do frango em todos os regimes. Com relação à elasticidade-renda, os resultados desta pesquisa são semelhantes aos apresentados por Resende Filho et al. (2012), com relação positiva e significativa, exceto no regime 4. Observa-se que os coeficientes aqui apresentados são maiores, indicando maior sensibilidade à alterações renda.

A estatística Durbin-Watson $(D W=1,9023)$ apresentou-se entre os valores limites esperados de 1,8549 e 2,14508 para amostra de 220 casos, demonstrando ausência de autocorrelação entre os resíduos da regressão. O teste de Dickey-Fuller Aumentado (ADF) dos resíduos rejeitou a existência de raiz unitária $(t=-15,1388$, sig. $=0,0000)$. $\mathrm{O}$ teste de Jarque-Bera rejeita a hipótese de normalidade dos resíduos $(J B=15,5681$, sig. = 0,0004). O teste de White rejeitou a hipótese de heterocedasticidade $(F=2.5433$. sig. $=0,0000)$ cumprindo o pressuposto de homogeneidade dos resíduos. $\mathrm{O}$ coeficiente de determinação $\left(R^{2}\right)$ ajustado apresentou valor de $98,77 \%$, denotando alto poder de previsão da regressão. 


\section{Considerações finais}

Utilizando o procedimento de Bai-Perron para localizar quebras estruturais, foi possível verificar que entre janeiro de 1995 e junho de 2013 ocorreram quatro quebras estruturais, resultando em 5 regimes. Essas quebras aconteceram em outubro de 1998, abril de 2002, julho de 2007 e maio de 2010.

No primeiro regime a demanda por carne bovina foi bastante elástica em relação aos preços, tanto interno quanto externo, da carne de frango e preço interno da carne bovina. Porém, elasticidade-renda foi mais significativa. No segundo regime a relação de preços externos foi inelástica. A elasticidade-renda foi significativa neste regime e houve impacto da taxa de câmbio. No terceiro regime a demanda foi inelástica em relação aos preços externos das carnes de frango e bovina e elástica aos preços internos das mesmas carnes. A taxa de câmbio também teve impacto significativo. No quarto regime a demanda foi elástica em relação ao próprio preço interno e inelástica em relação aos preços externo e interno do frango. A renda passa a ser novamente significativa. No quinto regime a demanda é elástica em relação ao preço externo dos suínos, interno do bovino e à renda. Houve tendência significativa de crescimento no segundo regime e de recessão no primeiro e terceiro regimes.

Deve-se ainda considerar que a alta concentração de exportações para destinos representa risco para o mercado brasileiro. Aproximadamente $58 \%$ das exportações foram para somente quatro países entre 1995 e 2012, gerando possibilidade de poder de monopsônio. A existência de maior número de compradores reduziria o poder de barganha individual, diminuindo a dependência dos vendedores brasileiros. Além disso, Rússia e Chile são países com economia em desenvolvimento aumentando o risco de negociação, pois são mais suscetíveis a crises econômicas, que podem afetar as relações comerciais. A troca de posições no ranking dos principais importadores e a inclusão de novos destinos de exportação pode impactar na elasticidade-preço.
Para o entendimento da demanda internacional de carne bovina, este artigo contribui no sentido de demonstrar que as relações entre os preços e as quantidades demandas não são estáticas. Em alguns momentos as relações diferem dos resultados empíricos de outras pesquisas, a exemplo dos trabalhos já citados, de Resende Filho et al. (2012) e Hupková e Bielik (2009), pois são influenciados por variáveis não incorporadas aos modelos, tais como renda dos países de destino, cultura, políticas setoriais, barreiras tarifárias e não-tarifárias.

Novas pesquisas devem ser realizadas incluindo diferentes variáveis e buscando novos meios de compreensão da dinâmica da exportação de carnes bovinas, incluindo abordagens não lineares para a investigação do problema, tal como Markov regime switching, e ainda, que se analise a elasticidade da demanda para os principais países de destino das exportações.

Existem algumas limitações impostas à pesquisa. Primeiro, os preços informados pelo banco de dados do MDIC são em dólares, desconsiderando o frete de destino (Free On Board - FOB). O frete é uma variável não disponível para acesso em bancos públicos. Porém, é uma importante variável de decisão de compra nos mercados de destino, pois, aumenta os custos de transação. Segundo, O crescimento vegetativo da população mundial aumenta naturalmente o consumo de carnes. Esse aumento não foi incluído como variável no modelo para não prejudicar os graus de liberdade do mesmo.

\section{Referências bibliográficas}

AZEVEDO, A. F. Z. e PORTUGAL, M. S. Abertura Comercial Brasileira e Instabilidade da Demanda de Importações. Nova Economia, Belo Horizonte, v. 8, n. 1, jul. 1998, p. 37-63.

BAI, J. e PERRON, P. Estimating and Testing Linear Models with Multiple Structural Changes. Econometrica, v. 66 , n. 1, jan. 1998, p. 47-78.

. e PERRON, P. Computation and analysis of multiple structural change models. Journal of Apllied Economics, v. 18, n. 1, 2003, p. 1-22. 
BARROS, G. S. D. C., BACCHI, M. R. P. e BURNQUIST, H. L. Estimação de equações de oferta de exportação de produtos agropecuários para o Brasil (1992/2000): texto para discussão n. 865. Instituto de Pesquisa Econômica Aplicada, mar. 2002. Disponivel em: <http:// www.ipea.gov.br/portal/index.php?option $=\mathrm{com}$ content\&view $=$ article\&id $=4408>$. Acesso em: 20 set. 2013.

BEEFPOINT. Índia tem maior crescimento na produção e exportação de carne assim como no PIB comparado com economias avançadas [Rabobank], 2013. Disponível em: $<$ http://www.beefpoint.com.br/cadeia-produtiva/ rabobank-mercado-de-carnes-da-india/>. Acesso em: 16 dez. 2013.

BUENO, R. L. S. Econometria de séries temporais. 2. ed. São Paulo: Cengage Learning, 2011.

CFA/MA. Coordenação de Febre Aftosa. Ministério da Agricultura. Febre Aftosa, 2013. Disponível em: < http:// www.agricultura.gov.br/animal/sanidade-animal/ programas/febreaftosa > . Acesso em: 29 nov. 2013.

DURBIN, J. e WATSON, G. S. Testing for Serial Correlation in Least Squares Regression: I. Biometrika, v. 37 , n. 3/4, dez. 1950 , p. 409-428.

e WATSON, G. S. Testing for Serial Correlation in Least Squares Regression. II. Biometrika, v. 38, n. 1/2, jun. 1951, p. 159-177.

FERGUSON, C. E. Microeconomia. Rio de Janeiro: Forense, 1989.

GALLET, C. A. The income elasticity of meat: a metaanalysis. The Australian Journal of Agricultural and Resource Economics, n. 54, 2010, p. 477-490.

. A Meta-Analysis of the price elasticity of meat: evidence of regional differences. Business and Economic Research, v. 2, n. 2, 2012, p. 14-25.

GREENE, W. H. Econometric analysis. 5. ed. New Jersey: Prentice Hall, 2002.

GUJARATI, D. N. e PORTER, D. C. Econometria básica. 5. ed. Porto Alegre: McGraw Hill, 2011.
HENNEBERRY, S. e MUTONDO, J. E. NAFTA Impacts on the U.S. Competitiveness and Trade: Beef, Pork, and Poultry. American Agricultural Economics Association Organized Symposium. Portland, Oregon. 2007.

HUPKOVÁ, D. e BIELIK, P. Estimating Demand Elasticities of Meat Demand in Slovakia. 113th EAAE Seminar "A resilient European food industry and food chain in a challenging world", Chania, Crete, Greece, 3-6 set. 2009.

IPEA. Instituto de Pesquisa Econômica Aplicada (Ipea). Ipeadata, 2013. Disponível em: <http://www.ipeadata. gov.br/> . Acesso em: 20 set. 2013.

MACKINNON, J. G. Numerical distribution functions for unit roor and cointegration tests. Journal of Applied Econometrics, v. 11, n. 6, p. 601-618, 1996.

MDIC. Ministério do Desenvolvimento, Indústria e Comércio Exterior. Exportação brasileira. Aliceweb, 2013. Disponível em: <http://aliceweb.desenvolvimento. gov.br/>. Acesso em: 02 set. 2013.

MEDEIROS, N. H. e OSTROSKI, D. A. Competitividade e concentração de mercado: uma análise da avicultura nas mesorregiões oeste e sudoeste paranaense. XLIV Congresso da SOBER, Fortaleza, 2006.

NEWEY, W. K. e WEST, K. D. A simple positive semidefinitive, heteroskedasticity and autocorrelation consistent convariance matrix. Econometrica, v. 55, n. 3, maio 1987, p. 703-708.

PINDICK, R. S. e RUBINFELD, D. L. Microeconomia. 6. ed. São Paulo: Pearson Prentice Hall, 2006.

RESENDE FILHO, M. D. A. et al. Sistemas de equações de demanda por carnes no Brasil: especificação e estimação. Rev. Econ. Sociol. Rural [online], 1, jan./mar. 2012, p. 33-50.

VARIAN, H. R. Intermediate microeconomics. 8. ed. New York-London: W. W. Norton \& Company, 2010.

WHITE, H. A Heteroskedasticity-Consistent Covariance Matrix Estimator and a Direct Test for Heteroskedasticity. Econometrica, v. 48, n. 4, mai. 1980. p. 817-838. 
